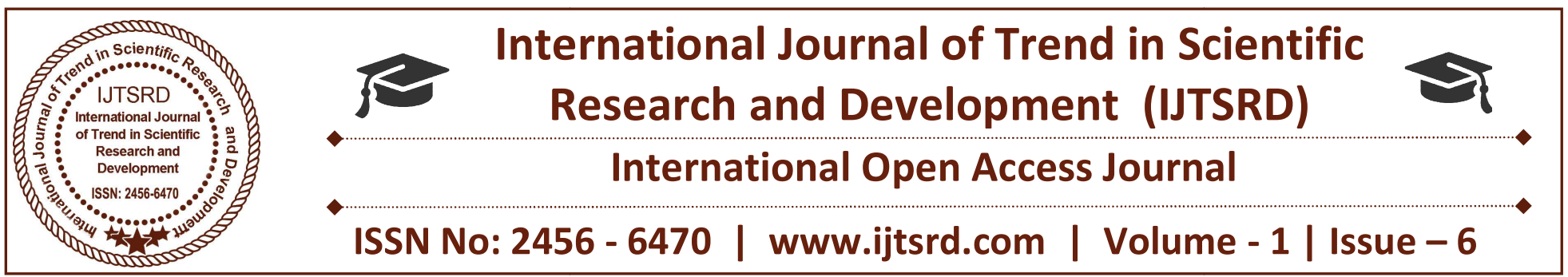

\title{
On Comparative Literature
}

\author{
Santosh Kumar Nayak \\ Junior Lecturer in Odia (OES-II) \\ Model Degree College, Malkangiri, Odisha, India
}

\begin{abstract}
Comparison is a common technique we go through in our everyday life. It is rather a human psychology. Even each animal looks with this vision. But more specifically, human being is much more developed cerebrally than others. CL actually exists upon the two traditions, called Little tradition and Great Tradition. It is such a tool by virtue of which we can enrich our National Literature and hence this kind of literature is named as Universal literature, Global Literature or Welt literature. Intellectuals like Tagore name this Visva Sahitya with a greater goal. Attempts have been made to bring out the methods, doctrines and perspectives of American, British, French, German, Japanese and other countries across the globe. What is Comparative literature, what are its objectives and the modus operandi- all these things are well discussed here.
\end{abstract}

Keywords: Comparative Literature (CL), Great and Little Tradition, National Literature, Welt Literature, Visva Sahitya, Universal Literature.

"Comparison and analysis are the chief tools of the Critic.” -Thomas Stearns Eliot

\section{INTRODUCTION}

COMPARISON is a natural human psychology. It is an as usual process a person looks, thinks analyses and comments. In this world, there are only two kinds of things, i.e. either same (similar) or different. To know this, when we see contemporaneously we compare mentally. Either to distinguish or to equalize we need to compare. This is the only common process in both the cases. This world has a great many kinds of things around us. How could we know this? ' $\mathrm{X}$ ' is different to that of ' $\mathrm{O}$ ', ' $\mathrm{B}$ ' is similar to ' 8 ', ' $\mathrm{W}$ ' is similar to ' $M$ ', ' $C$ ', ' $D$ ', ' $G$ ' are similar to 'O' similarly ' $L$ ', 'I', 'T' are similar to each other etcetera. All these things came to mind due to the natural and instantaneous process called 'Comparison'. The final decision or the conclusion came only and only due to 'Comparison'. It is obvious that human beings are expert than other animals of this earth in comparison and finding the conclusion. The concept of diversity and again unity, even if the concepts like specialty, uniqueness, best, better, worse, worst, and all the adjectives come under this technology called Comparison. But the question is that whether doing comparison is CL. No, not at all. Technically and gloss logically, Comparative Literature (CL) is not at all the simple comparison between the literatures (i.e. $\mathbf{L}^{\mathbf{1}}$ and $\mathbf{L}^{\mathbf{2}}$ ). Technically, the glossary of CL goes against this philosophy in general. It is also not that to compare the two literatures in order to prove one's excellence and to say one of them better than the other. To advocate for the literature of the mother tongue and to criticize others' is not a healthy practice at all which had been a so called trend of Indian criticism one day. Some were there who told it CL but it is not at all true and it has been disproved by the other weapons of criticism later. Now-a-days, CL is a specialized discipline of literature having a great responsibility on its shoulder.

\section{UNDERSTANDING THE DISCIPLINE AND ITS ROOT}

Comparative study is one of the wonderful gifts of anthropology to each and every discipline of the 
world. The main source of this discipline comes from anthropology and further it has been entered into the domain of literature. Due to chemistry with the various sub-disciplines of literature CL has now taken such a shape which is quite different from the early one or the original one and has a quite unique identity.

The culture of CL or the philosophy of CL is nothing but to shape the self. It is something which means to enlarge the sight and chest of self for the sake of others. Because, CL needs a greater thoracic cavity to keep others' tradition, culture, language and literature. We need to come out from the narrowness of our own sight and should see the self in a greater whole. We can see the 'proper self' if and only if we can see ourselves in a greater sightedness beyond the narrow thinking of 'yours' and 'mine'. We need to know more and more. We, for this only, should know the religion, language, literature, tradition, culture, race, social doctrines, societal values and ethics, their morality and modalities and all such things. Then only we can enter into the domain and range of CL. Instead, if we will know a little and will only know ourselves, then we can't recognize ourselves properly. The result we find at that time about us may be partially true due to our limited knowledge. The 'self' is inside the 'universe'. Though individuals make a whole but after the formation of the whole, the individuals lose their identity (like a water droplet and the ocean). Hence, the knowledge of the whole or universe we can properly recognize the self (individual). This is the scope where we can know the self better and much closer than ever. Anthropology defines the same thing with the illustration of two things: Great Tradition (GT) and Little Tradition (LT). Here, it has been illustrated that we can know the LT by virtue of the GT.

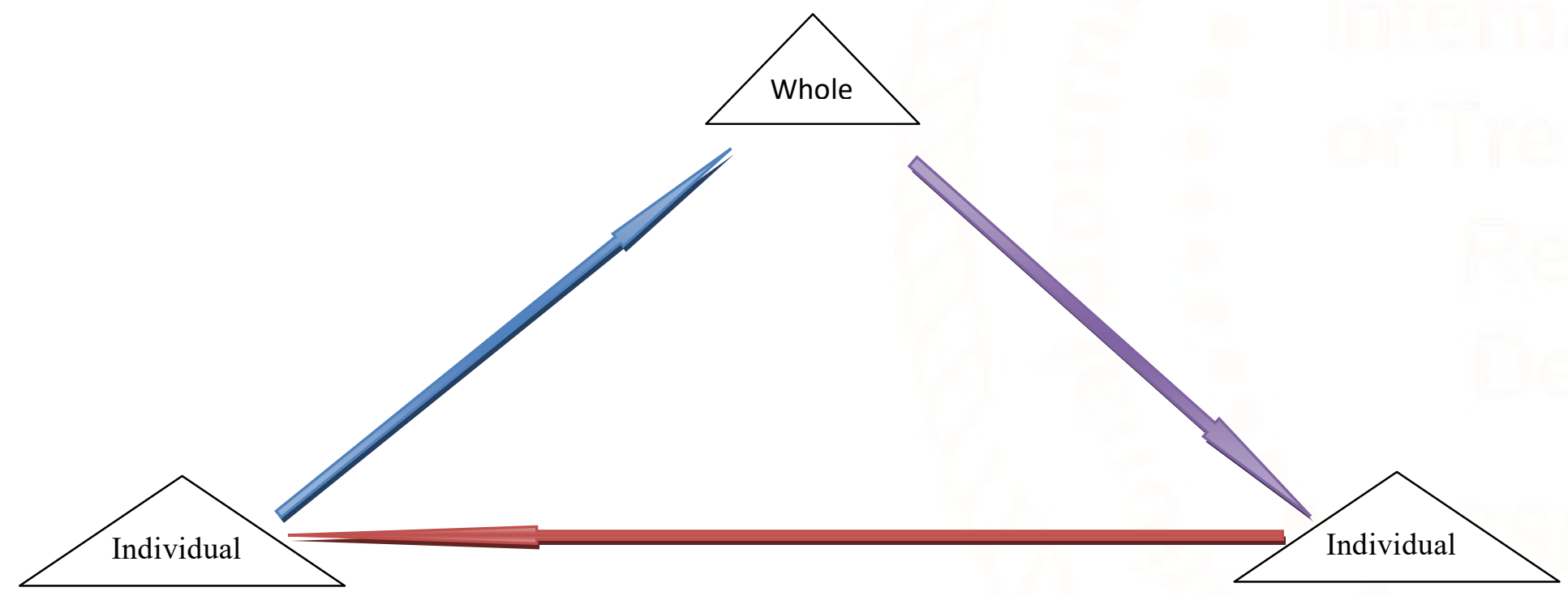

[ Fig. 1.1 - Model showing the technique to know the LL/RL/Self through the CL Technology ]

To know and recognize the literatures of across the world with respect and reference to their culture and tradition which are related to our literature is said to be the real goal of CL. To know the literature of ourselves inside a greater circle is the original task of CL. We can take for an instance of Odia Literature. Whenever we read and recognize the same, we just measure it with reference to the culture, tradition, language and other literary works of the same geographical territory, language and literature made earlier. But it is not the right process to measure the same by the tools of CL. In another words, with the help of Slide Caliper and the Screw Gauge of CL we need to measure the intellectual and artistic height and width of the work with reference to the other peripheral literatures, traditions and environments. In case of Odia literature, we need to go into the Bengali literature, Assamese, Marathi, Malayalam, Telugu, Tamil, Gujrati, Konkani and other states' literatures and their cultures. Again, we have to measure and perceive the same literature with respect to the world literatures. English, French, Germany, Greek, Canadian and other literatures should also be gone through. After all these things we can have a look of that CL. Then only we can know ourselves truly and we can know us the best. This is how CL could be explained and tasted the best. 


\section{OBJECTIVES AND FORMS OF CL}

CL is the means to build a healthy and wealthy National Literature (NL). NL of a nation can be enriched only and only by its perspectives not by increasing the number of creations or books etcetera. Literally, to enrich and enlarge a national literature, we need to go beyond the little and limited surrounding of self and synchronously we have to know the vast world (i.e. to know and recognize and to make out and accept the language, literature, culture, tradition, customs, socio-economic status etc. of the different sects of the whole world) with a global approach, which will enable us to see and measure ourselves relatively in a better way. In this way, CL has a pivotal and significant role in making the NL rich and time-worthy. The background of CL is very important in order to sustain the literature of the self, i.e. the Local Literature (LL) as well as to sustain the NL or RL. Behind all these things, as a background we have one thing at our hand and that is the way we see the world. This determines the standard of the LL, RL and even of the NL.

Here, LC is equally important to that of the NC. The consciousness of the both must be there within us. For this only, some of the cerebral critics of the world sketch the pattern of whole literature of the world as CL versus $\mathrm{WL}$ or $\mathrm{LL}$ versus $\mathrm{NL}$ etcetera. NL represents the voice and existence of a nation. It has that much of potency to narrate a nation, its internal heart and soul. One thing is very clear from this episode that each and every literature has its birth as a LL or RL. But the comparative perspectives make it enable to be classic literature, to which we say WL or Welt Literature.

The intellectual expedition from the self to whole, from the lightlessness to light even from the local to global is termed as renaissance. It is same in all way from Europe to Odisha. In case of the European and Odishan renaissance we find the very same thing. This is the mother source of the philosophy of CL. Comparison is an art itself which is as old as humanity. This has been a serious discipline and a momentous technique today since it has a prominent and paramount part to play in the modern world. Today, comparison has been honoured as a branded technique in each and every sphere of life. In simple words, it has become a trend, fashion or even a dire necessity today. We need to find out the link of CL from the great philosophy of Renaissance. The diction or the technical term 'Comparative Literature' was used (or came to the limelight) in English for the first time by Mathew Arnold in 1848, when he was translating the French writer's words, 'Historie Camparative'. In his Inaugural Lecture at Oxford in 1857, he said:

\section{"Everywhere there is connection, everywhere there is illustration. No single event, no single literature is adequately comprehended except in relation to other literature." 1}

In fact, no literature is free from the other. The reasons are: (a)The source(s) of the literature(s) $\mathrm{L}^{1}$, $\mathrm{L}^{2}, \mathrm{~L}^{3}$, and $\mathrm{L}^{\mathrm{N}}$. (b) The human knowledge. An author will write on the basis of his acquired knowledge and self vision. Every writer is present in his every work and $\mathrm{s} /$ he speaks something in it compulsorily. But each of them could not be a master piece or a literature from within the world/global literature (GL). This is only because of the vision. The immortal and global vision of an author can make his literature enable to live long even forever being a part of the GL or WL. In spite of the great difference of Languages, cultures, traditions and individual talents the reader can recognize the open and global resonance of the particular piece of literature. When the reader reads such great works of the writers, all the differences vanish and the art of the artist works as a bridge between two or more different socio-geographical lands. The work and the artistic vision soon becomes a tool for the unity across the world. In, this way CL is a bridge-like network which connects the whole world. Hence, the German Poet Goethe, once told this literature 'Welt Literature' where Arnold told this 'Comparative Literature'. The World-Poet Rabindranath Tagore had named it 'Visva-Sahitya' which also means the same whereas Van Tieghem prefers to use the alternate term 'Synthetic Literature'. H. H. Remak says 'Universal Literature' to this CL in his way to which I accept and believe as a GLOBAL LITERATURE. This is beyond the narrowness of the regional and personal degrees and doctrines. Here, it could also be concluded that nothing is tagged as good or bad literature, nothing is branded like RL or GL. Rather every literature takes its birth as a RL and it gets converted to GL on the basis of its potency. The potency of the literature though remains from the very first day, still it takes the honour of GL when and only when it is deemed and criticized by some one and brought to the limelight as a universally accepted piece. Here, the RL becomes the WL or GL. 


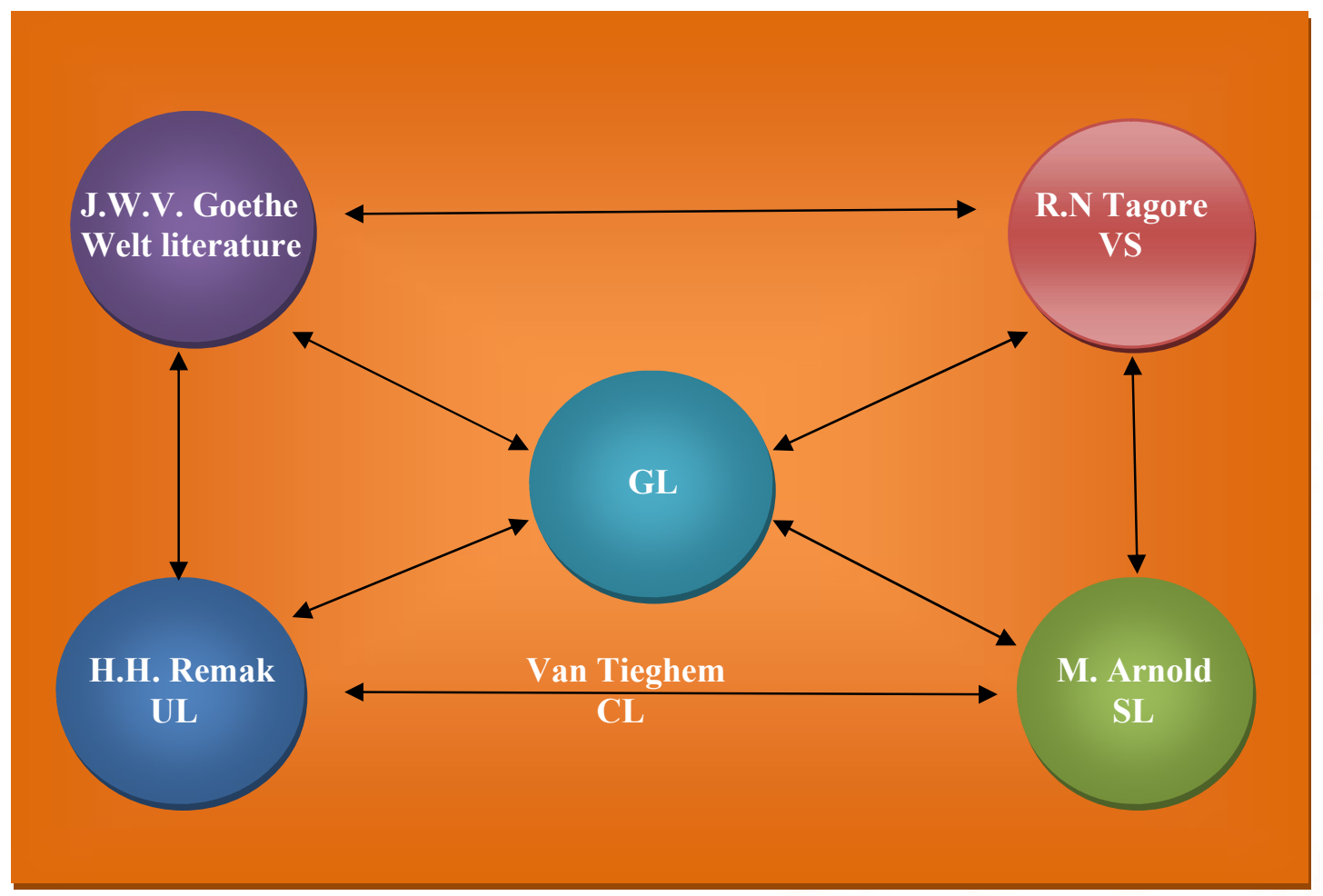

\section{[ Fig. 1.2 - Model showing the interlinks between WL, VS, UL, SL, CL \& GL ]}

R.N. Tagore had a greater thought in a greater perspective. He took the philosophy of literature as a whole. No philosophy is absolutely isolated according to him. That means, when a piece of literature, i.e. a poem/story/essay/drama/novel or any creation takes its birth it has its link automatically with other things. It is just like a human baby and her/his link with the environment. Hence, nothing is absolute. Nothing is isolated. Everything is connected with each other. When Tagore thought of this 'VS', CL was still in its infancy in Europe and America as an academic discipline. When scholars of CL tried to introduce it as an academic discipline in several universities just like other disciplines, it was vehemently opposed by many scholars of eminence. They opposed it because at that time CL had neither been accepted as a fullfledged discipline nor as a different one than any literature. Buddhadeva Bose, in his essay "Comparative Literature in India", has given a crystalclear idea which is reproduced right here in an abridged summary below:

"If we want to understand man as revealed in action, his motivation and his aims, then we must pursue his intensions through the whole of history. To take isolated instances, such as the reign of Akbar or Queen Elizabeth, is merely to satisfy curiosity. He who knows that Akbar and Elizabeth are only pretexts or occasions; the man, throughout the whole of history incessantly at work to fulfill his deepest purposes, and to unite himself with the All-it is he, I say who will strive to see in history not the local and the individual, but the eternal and universal man. His pilgrimage will not end in observing other pilgrims, for he will behold the god whom all pilgrims are seeking. What I am trying to say amounts to this. Just as this earth is not the sum of patches of land belonging to different people, and to know the earth as such is sheer rusticity, so literature is not the mere total of works composed by different hands. Most of us, however, think of literature in what I have called the manner of the rustic. From this narrow provincialism we must free ourselves; we must strive to see the work off one another as a whole, that whole as a part of man's universal creativity, and that universal spirit in its manifestations through world literature. Now is the time to do so." (243-44)

The tem CL was taken as a bogus one in its early introduction days. It was the third decade of the twentieth century when there was proposal to change 
the name of the English department of Cornel University, USA into Department of Comparative Literature. But this was strongly opposed by the head of the department Lane Cooper. Even he denied to be the head of the further changed department as was simply a bogus term for him. Rather he had a suggestion. It should be 'The Comparative Study of Literature' instead of 'Comparative Literature', said Cooper. Still, a number of departments were opened in this name. in some places 'Department of English' became 'Department of English and Comparative Literature' and in some other places this term was added with the departments of Germane, Slavic and Romance etcetera. F.W. Chandler and J.E. Spungarn, the professors of Columbia University, Harry Levin, the professor of Harvard University, Rene Welleck and Austin Warren, the professors of Yale University are the eminent scholars of CL. The argument made by Cooper was was not effective as he did not focused on the evolutionary meaning of the term 'literature'. Cooper thought only on the literal meaning of 'literature' and made an argument for the word 'comparative', which is an adjective, and its use before 'literature'. But from $200 \mathrm{AD}$ to $300 \mathrm{AD}$ and from $18^{\text {th }}$ to $19^{\text {th }}$ century the term has gone through a series of metamorphoses in meaning. Hence, the professors and scholars of CL remained a little flexible with the term 'LITERATURE' and its meaning. Therefore, everybody accepted the term 'Comparative Literature' instead of 'The Comparative Study of Literature'. Now-a-days, as a subject CL forms the part of the curricula of so many universities of the world. In India it is popular since last sixty two years. The first department of CL in India came into existence in 1956, at the Jadavpur University, Kolkata. In 1974, Delhi University started a department for Masters Degree named 'Comparative Indian Literature' with a view to the modern Indian languages. Soon after the term CL became popular in various universities of India. The concept of 'modern India' and the rise of the consciousness of 'modern Indian nationalism' functions as a strong back-ground of CL in India.

\section{CL BEYOND NATIONS}

Comparative study or comparison of any two or more things in any field is a common and natural phenomenon. Comparative Study of literatures is a phase wise/ systematic reading of the 'text' and 'context' both. Comparative study in literature, confines to the study of relationship between two or more literatures (between $\mathrm{L}^{1}, \mathrm{~L}^{2}, \mathrm{~L}^{3}$ and $\mathrm{L}^{\mathrm{N}}$ ) along with their socio-cultural back-grounds. It is the study of literature beyond the confines of an anthropogeographical territory. One of the best critics of CL, Susan Bassnett says,

"[...] Comparative literature involves the study of texts across cultures, that it is interdisciplinary and that it is concerned with patterns of connection in literatures across both time and space." (1)

Bassnett at the same time bring forward the arguments of Croce. He personally attacked and opposed vehemently to the suggestion that CL should be treated as a specific and allied discipline. Says Bassnett, in a discursive form-

"Benedetto Croce argued that comparative literature was a non-subject, contemptuously dismissing the suggestion that it might be seen as a separate discipline. He discussed the definition of comparative literature as the exploration of 'the vicissitudes, alterations, developments and reciprocal differences' of themes and literary ideas across literatures, and concluded that 'there is no study more arid than researches of this sort'. This kind of work, Croce maintained, is to be classified 'in the category of erudition purely and simply'. ${ }^{2}$ instead of something called comparative literature, he suggested that the proper object of study should be literary history." (2-3)

He took the thing just as a comparative study of different aspects i.e. various dimensions and angles of the literary works. In the very same year Charles Mills Gayley, one of the founders of North American Comparative Literature (NACL), proclaimed like Croce's attacking voice that the working premise of the student of CL was:

"Literature as a distinct and integral medium of thought, a common institutional expression of humanity; differentiated, to be sure, by the social conditions of the individual, by racial, historical, cultural and linguistic influences, opportunities, and restrictions, but, irrespective of age or guise, prompted by the common needs and aspirations of man, sprung from common faculties, psychological and physiological, and obeying common laws of material and mode, of the individual and social humanity.,"3 
The American and the French "schools" both accept the opinion that CL lives beyond the national territories. Says Remak, "[...] there are important variations of relative stress in its practical application."(4) S.S. Prawer writes in the Comparative Literary Studies, that comparative literature implies a study of literature which uses comparison as its main instrument. Of course a comparative perspective or a comparative attitude must be there when we are dealing with CL. Remak defines the term broadly,

"Comparative literature is the study of literature beyond the confines of one particular country, and the study of the relationships between literature on one hand and other areas of knowledge and belief, such as the arts (e.g. painting, sculpture, architecture, music), philosophy, history, the social sciences, (e.g. politics, economics, sociology), the sciences, religion, etc., on the other. In brief it is the comparison of one literature with another or others, and the comparison of literature with other spheres of human-expression."(3)

$\mathrm{CL}$ is a method of the study of literature, a special discipline having its own objectives, perspectives, methodologies, tools and techniques. There are at least two ways to study with eyes of CL. He further writes,

"First, Comparative literature means the knowledge of more than one national language and literature, and /or it means the knowledge and application of other disciplines in and for the study of literature and second, Comparative literature has an ideology of inclusion of the other, be that a marginal literature in its several meanings of marginality, a genre, various text types, etc. Comparative literature has intrinsically a content and form, which facilitates the crosscultural and interdisciplinary study of literature and it has a history that substantiated this content and form." (1)

On the basis of above discussed decorum and criteria a quality centric firm conclusion may be drawn that $\mathrm{CL}$ is an intellectual discipline dealing with the different literatures of two or more different ethnic, linguistic, socio-cultural or national groups. Comparative study of literature (CSL) may also be performed on works of the same as well as different languages, society, nations or cultures. Some of the critics say that comparison is a method used by all criticism as it a spontaneous process that occurs in the head and heart of a critic even it happens in case of every reader. Yes, of course it is silent about any specific conducts or procedures of literary study. How e ver, CSL is the study of oral (folk) literature, relationships between two or more literatures and literature in its totality with respect to the 'world literature'.

CL could not be simply defined as an inevitable stage in reading. It is not the internationalization of a particular book or a piece of literature. It is not even the wide availability of translation of a masterpiece nor anything in that light. Yes, we can rightly remember here the words of Goethe:

"It is becoming more and more obvious to me that poetry is the common property of all mankind."

Here, one thing must be very obvious and clear that the poetic beauty, which is inherently attached with aesthetics, is open to access for one and all. Everybody can enter into the hive and suck the honey if he has that much of ability. It means, this is not confined to any particular geographical territory. So it is a common property. One thing or the similar thing could be thought at the same time by two different persons of the different areas of the globe without any influence. Similarly, one could be affected by other and can write the similar thing there-after. Says Bassnett,

"But if we shift perspective slightly and look again at the term 'Comparative Literature' what we find instead of history of violent debate that goes right back to the earliest usage of the tem at the beginning of the nineteenth century and continues still today."(2)

A comparative literature study does not mean at all that it should have to be comparative on every page, line by line nor even in every chapter, but the overall intent, magnitude, motive, emphasis and execution must be comparative. Says Remak,

"The assaying of intent, emphasis and execution requires both objective and subjective judgment. No rigid rules can and 
should, therefore, be set down beyond these criteria."(15)

CL is a specific approach to the phylum of literature with a special reference to the kingdom of culture and the order of tradition associated with it. Again, it is less critical and more analytical as well as suggestive by nature. The approach which is made over here is literally analytical, descriptive and synchronic, and not historical and genetic. To be more particular, we can designate this as the syndrome of CL that usually we find. Here we will find the definitions and the perspectives regarding the definition and the meaning of CL. Leading scholars like Fernand Baldensperger, Jean-Marie Carré, Paul Hazard, Paul Van Tieghem, as well as Marcel Bataillon, Charles Dédéyan, Henri Roddier, Basil Munteano, M.-F. Guyard, and others have propounded the theory in this way. Van Tieghem, Carré and Guyard have been held responsible for the principal formulations of contemporary French comparative theory and policy (FCTP). Special care has been taken to concentrate in this essay on problems with it in those portions contrasting American with European trends of Comparative Literature (AETCL). Because these two schools have literally different trends, different dogmas and belief. In each case the modus operandi is important.

Many folklore studies are comparative par excellence as during the examination of motifs the folklorists use these techniques of CL. It is because there is a possibility again of coincidence against the probability of influence. In the theory of CL, we find some wavering in the doctrines and modus operandi particularly. Another research scholar of CL, Guyard says that there has been a serious movement toward the aesthetic appreciation of literature in these days. He further concedes that influence studies and vast syntheses are necessary for this discipline, and even marks a place for "coincidence" studies. Van Tieghem, while excluding "coincidental" comparisons from CL, somewhat arbitrarily welcomes them to "General Literature". Recently, certain French scholars like Bémol, Etiemble etc. have accosted the conventional grails of French comparatism, both in writings as well as in the debates of the First French Congress of Comparative Literature (FFCCL) of Bordeaux, 1956 and of the Second International Comparative Literature Congress (SICLC), Chapel Hill, 1958. Moreover, some influential and pre-eminent French spokesmen at the latter meeting as Frappier, Roddier, Munteano,
Escarpit, etc., while defending the doctrines, stances, various convictions and perspectives of French Comparative Tradition (FCT), are cognizant of its past and potential abuses and are suggesting some new applications of their modus operandi that incorporate some of the doctrines and canons of the "American school." At the FFCCL held in Bordeaux in March of 1956, Basil Munteano, one of the great critic of the century, established the relationship between literature and the other arts to "general literature"( Littérature générale et Histoire des idées, 1957 , p. 25). Again, if we will notice deeply, we will see in America, too, theory and practice are not identical. Majority of the American scholars, including those in CL do their research along more or less traditional historical lines. We cannot draw a firm line any way to make out CL within a specific sphere. More specifically, to the American comparatist, such a 'lack of logical coherence' would be more apparent than real, for he would see a fundamental link between the inclusion of 'literature and the arts,' 'literature and music,' etc. in CL, and the 'analogy inside literature' approach recognized by American practitioners: in both cases, comparison brings out the inherent or potential characteristics of literature.

The terms 'international literature' and 'universal literature' are somehow synonymous with 'world literature', but have not been able to establish themselves yet. ${ }^{5}$ Werner P. Friederich suggests that CL scholars might well restrict themselves to the "French system" in teaching but could indulge in the "American point of view" in their researches. ${ }^{\mathbf{6}}$ This is in fact a very important perspective he has given. Julius Petersen says that any treatment of a foreign literature is, in a way, comparative by nature, inasmuch as it utilizes, consciously or unconsciously, criteria derived from the writer's own national environment. ${ }^{7}$ This is somehow a true observation, but it is very clear that the comparative angle of a literary study must be more and more explicit rather than implicit if we are going to have standards at all. The Italian and English concepts of CL accept and follow the French ideas quite closely. English comparative perspectives seems somewhat less restrictive than French in its greater attention to the literature of the middle ages, although the original French position which excluded antiquity and the middle ages from CL has undergone a revision in the last fifteen or twenty years. ${ }^{\mathbf{8}}$ Italian comparatists, due to the influence of Croce, do not hesitate to emphasize the aesthetic corner of literature despite 
their general adherence to French models. The trend in Germany, just as in the United States, is very decidedly in the direction of literary criticism, i.e. with a kind of critical perspective. Japan, long beholden to the French tradition, is veering in the American direction. ${ }^{9}$ In toto, there are only two kinds of perspectives basically all over the world.

August Wilhelm von Schlegel's pioneering Lectures on Dramatic Art and Literature (1808) are the basic assets of CL. These belong to the terra firma of CL not because they cover the literatures of Greece and Rome in the first, and the literatures of Italy, France, England, Spain and Germany in the second volume, although, were they restricted to independent discussions of these literatures, his essays would still become the assets of study of CL. They are CL because in his first lecture, he compares not only Greek with Latin dramas but the classical with the romantic dramas too, and brings in the Spanish, Portuguese and German dramas there. Because he constantly refers back to the classical literatures when he treats the Italian and French literature and avails himself of every opportunity to draw general comparisons between the dramatic literatures of England and Spain, of Spain and Portugal, of France and Germany, etc. with consistently keeping the general polarities of the drama in mind (i.e. tragiccomic, poetical-theatrical, "Ernst und Scherz" etc.); because, wherever possible, he directs attention to the fine arts these lectures are included in CL by the so called experts. It is the combination of these factors which makes this work clearly comparative. In this way, A. W. von Schlegel has established a very good example of comparison which belongs to the terra firma of CL.

\section{CONCUSION}

On the basis of above criteria and discussions we can have a firm conclusion and idea regarding the natures, forms, features, methods and perspectives of Comparative Literature. CL is what it does. It is the socio-cultural matrix that decides the nature of a particular literature. CL just brings that into limelight with reference to another one. The cultural aspects underneath the texts, the societal and political backgrounds or the settings beneath those texts are important. These are the objectives of a comparatist at one hand where as there factors are the subjects in disguise of the texts at the other.

\section{NOTES:}

1 Matthew Arnold, On the Modern Element in Literature, Inaugural Lecture delivered in the University of Oxford, 14th November 1857.

2 Benedetto Croce, 'Comparative Literature', 1973, 215-23.

3 Charles Mills Gayley, 'What is Comparative Literature?’ Atlantic Monthly, 92 (1903),pp 56-68.

4 Johann W. Von Goethe, 'Some Passages Pertaining to the Concept of World Literature', in Hans Joachim Schultz and Philip H. Rhein (eds) Comparative Literature: The Early Years, Chapel Hill, University of North Carolina Press, 1973, pp 3-11.

5 The Dutch scholar J. C. Brandt Corstius gives, in his De Muze in het Morgenlicht, Zeist, 1957) pp. 14970, an excellent account, both descriptive and critical, of the evolution of the term "world literature" from the threshold of history via Herder and Goethe to the twentieth century.

6 'Zur Vergleichenden Literaturgeschichte in den Vereinigten Staaten' in Forschungsprobleme der Vergleichenden Literaturgeschichte, II, eds. Fritz Ernst and Kurt Wais, Tübingen, 1958, 186.

7 See Die Wissenschaft von der Dichtung, Berlin, 1939, I, 7.

8 See Jean Frappier, "Littératures médiévales et littérature comparée: problèmes de recherche et de méthode, in the Proceedings of the Second Congress of the International Comparative Literature Association, Chapel Hill, 1959, I, 25-35.

9 See the Yearbooks of Comparative and General Literature, the Forschungsprobleme der Vergleichenden Literaturgeschichte I and II, the Revue de littérature comparée, JanuaryMarch, 1953, and the Congress Proceedings to know the modus operandi and perspectives of different countries of the world regarding CL.

\section{WORKS CITED}

1). Bassnett, Susan, Comparative LiteratureA Critical Introduction, London: Blackwell Publishers Ltd., 1993.

2). Bose, Buddhadeva, "Comparative Literature in India", Yearbook of Comparative and General 
Literature, 8.1959; also included in Contributions

to Comparative Literature: Germany and India, ed. Guha, Naresh, Jadavpur: 1979.

3). Prawer, S. S., Comparative Literary Studies, An Introduction, London: Duckworth, 1973.

4). Remak, Henry H. H., "Comparative Literature, Its Definition and Function", Comparative Literature: Method and Perspective. ed. Horst Frenz and Newton P. Stallknecht Carbondale, IL.: Southern Illinois University Press, 1961 